
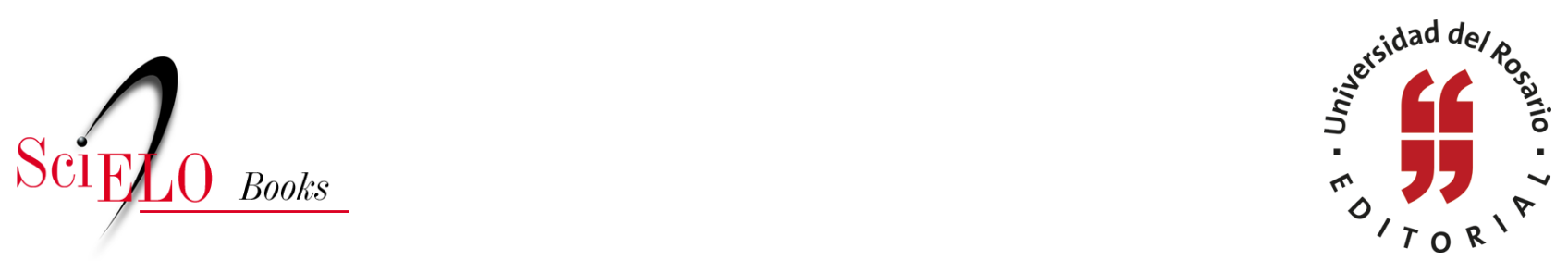

\title{
34. A mi papá le tiemblan mucho las manos
}

\author{
César Augusto Tapias Hernández
}

\section{SciELO Books / SciELO Livros / SciELO Libros}

TAPIAS HERNÁNDEZ, C.A. A mi papá le tiemblan mucho las manos. In: Historias de familia: Etnografía delirante sobre el amor, la violencia y las drogas [online]. Bogotá: Editorial Universidad del Rosario, 2014, pp. 147-150. Textos de ciencias humanas collection. ISBN: 978-958-738-543-4.

https://doi.org/10.7476/9789587385434.0035.

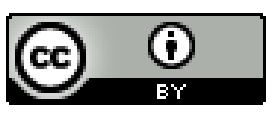

All the contents of this work, except where otherwise noted, is licensed under a Creative Commons Attribution 4.0 International license.

Todo o conteúdo deste trabalho, exceto quando houver ressalva, é publicado sob a licença Creative Commons Atribição 4.0.

Todo el contenido de esta obra, excepto donde se indique lo contrario, está bajo licencia de la licencia Creative Commons Reconocimento 4.0 . 


\title{
34. A mi papá le tiemblan mucho las manos
}

\author{
Mi corazón se estremece oyendo de nuevo estos gemidos; un \\ oscuro temor me penetra hasta las entrañas cada vez que escucho \\ tu voz, y siento desvanecidas mis esperanzas. \\ Esquilo, Las coéforas
}

A mi papá le tiemblan mucho las manos. Difícilmente puede tomar su taza de chocolate sin derramar algo, y el temblor de su pulso lo hace incluso achantar... Yo no puedo mirarlo siquiera de frente. Aun sin proponérmelo, recuerdo sus regaños, cuando de niños, ni Carlos ni yo podíamos con nuestras tazas que entonces resbalaban de entre nuestras manos y el chocolate corría por la mesa, sobre el mantel, sobre nuestras piernas...

Y él, todo enojado...

A Luis Alberto Tales Cárdenas, el mayor de los hijos de Fonso y Gélica, le tocaba ir caminando hasta el colegio, de El Pedregal hasta el Estadio. Pero esas caminadas finalmente no fueron tanto tormento para él. Estudió en el Marco Fidel hasta tercero de bachillerato y no terminó siquiera ese año, porque si bien era bueno en las matemáticas, la dicha le duró hasta que conoció el álgebra; sin embargo, años más tarde, la geometría, la trigonometría, lo respaldarían en su carrera. Y dice Tales muy contento y orgulloso que al menos estudió...

-En esa época, la gente, a duras penas, terminaba la primaria, güevón, y eso que los que estudiaban eran personas ya adultas que se interesaban en salir adelante... Yo me pongo a ver lo que estudiábamos nosotros y lo que les enseñan a ustedes... Eh, ave María, llave...

Pero caminando no solo el cucho iba al colegio, hasta donde fuera iba caminando primero, después en bicicleta, a ver pasar la vuelta a Colombia, por ejemplo.

—Eran los tiempos de "Cochise” Rodríguez y "Pajarito" Suárez. 
Se trataba de una disputa entre titanes donde la radio y los periódicos eran cómplices-informadores y amplificadores de pequeñas grandes cosas con las que soñaba este país. Por esos días, casa donde hubiera radio, era casa de ricos, y el cucho pagaba diez centavos donde una vecina de la otra cuadra por oírse las carreras. Por entonces, Tales recogía tapas de los productos Pilsen y en el camión de la cerveza las cambiaba por una libreta con estadísticas y datos de las etapas, de los corredores y de la historia de la competencia. Tal vez desde ahí fue que conoció el alcohol... Y en esa libreta, del tamaño de la mano, anotaba los datos de cada etapa y de la clasificación general, seguro con más rigor que las fórmulas matemáticas, seguro con la misma dedicación con que años más tarde dibujara bobinas y toda clase de motores... Luego del colegio, asegura mi papá, que no capaba clases, era cuando iba al velódromo del estadio para ver entrar a "Cochise".

-Era tan bueno ese man, que competía él solo contra cinco más...

Y mi cucho no se aguanta las ganas y va a la biblioteca y saca de entre sus libros, su carpeta: las libretas esas con los datos de la Vuelta a Colombia en sus versiones XIV, XV, XVI, XVII, XVIII, XIX y XX y muy entusiasmado fue sacando luego las notas de sus años en el Sena.

En la biblioteca de la casa, desde el principio, el cucho se ha procurado un lugar para sus papeles-recuerdos de otros años... El cucho se fue al Sena a estudiar Electromecánica y Redes con el patrocinio de las Empresas Públicas de Medellín. Y siempre fue uno de los mejores. Sus estudios los hizo en el Sena de la ciudad de Cúcuta, entre 1968 y 1971. Sin terminar la secundaria, mi cucho se dio a hacer una tecnología mientras el mundo se organizaba en batallas de todo tipo y calibre, reclamando libertad —eran los tiempos de la Guerra Fría-, y cerca, muy cerca, estuvo el cucho de palpar esas protestas que al mundo le abrieron la mente: Tales era tan bueno en geometría y trigo, sus planos de circuitos eléctricos, transformadores y bobinas quedaban tan bien, que los franceses que asesoraban su carrera le ofrecieron irse a la Galia solo si renunciaba al patrocinio...

Pero al cucho siempre le han gustado las cosas serias y aseguradas. ¿Por qué desechar el futuro que le aseguraba la empresa gracias a la cual estudiaba? Mi papá entonces no se fue a Francia, y eso nunca le ha pesado. Fue mejor quedarse recibiéndoles clase a grandes maestros de la vida como el profe Arteaga.

-Arteaga era maestro de matemáticas, uno tan bueno que les daba clases a los demás profes... Enseñaba al escondido, porque todo el mundo lo buscaba. Era tan conocido que estaba garantizado que nunca nadie le daría trabajo... Arteaga diseñó el Plan de Asalto al Cantón Norte. Allí el “eme” le robó al Ejército nacional un 
verdadero arsenal para la guerra... El Sena escondía a Arteaga con tal que enseñara, y yo fui su amigo...

El profe Arteaga hubiera podido falsear el diploma que nunca consiguió papá, me cuenta; pero ya era muy tarde cuando supo que el cucho no era bachiller... Si se lo hubiera conseguido, fijo el cucho hubiera podido ir más allá de Francia... pasar los Alpes, tal vez...

El gusto y el encanto del cucho por la vida, por mucho tiempo lo manifestó con el deporte. Nunca fue ciclista, pero corrió en más de una ocasión como atleta representando a las Empresas Públicas... Hasta se ganó un trofeo que con el tiempo terminó recibiendo del tiempo solo polvo... Las canchas de fútbol lo vieron corretear el balón con destreza cuando ya empezaba a crecerle la barriga y a notársele su nueva condición: empleado, casado, con hijos... Por la casa, montó con unos amigos un equipo superpoderoso que contaba con barra y con uniforme... el Jardín se llamaba: de camisa blanca y azul... como el Millos, aunque el cucho es hincha fiel del Medallo... Entonces era el futbolista que papito Fonso no le dejó ser, que era una pérdida de tiempo, le decía Fonso, correteándole el balón a mi papá... Le tacaba esconder los guayos y postergar la esperanza.

Un día, almorzando y oyendo radio, el cucho lanza su opinión frente el sistema social y político de nuestro país:

- A un Estado democrático no le interesa el deporte, ni la cultura, solo piensa en los puestos que ocuparán políticos baratos que no hacen más que robar... Ahí está la Vuelta a Colombia, que después de cincuenta años nunca ha sido un negocio rentable cuando en el mundo entero el ciclismo solo por decir el Tour de France es el segundo mejor negocio después del fútbol...

Esa es la opinión del cucho, que no deja de admirar países como Cuba, Rumania y la antigua Checoslovaquia, por su impulso al deporte y a la competencia. Aunque es seguro que la fijación del cucho va por encima de cualquier miramiento ideológico.

Pero un día, el cucho terminó embebido de alcohol. Y ese se volvió su nuevo culto... Y en pleno apogeo de la embriaguez no teme herirse o herirnos. Al preferir y desear morir borracho, bebiendo... ¿cómo se sentirían los familiares de Allan Poe, de Hemingway, de Bukowski... viéndolos morir?

No dejo de pensar en qué lugar habría escondido mi padre sus viejos guayos; supongo que algún vecino, o en un hueco junto a la Tinaja, la cancha de por su casa... al término de los años, tras elegir el alcohol, se le extravió la esperanza, el balón, el amor... 
Entonces, la radio de una vecina, su cicla pinchada por la Policía, la abuela, sus hermanas, el amor de mi mamá, el destino sobre la piel, se volvió alcohol y puños...

Extrañas formas de amor o de morir viviendo.

$\infty \infty \infty$

El tema más estratégico en todo el pensamiento de Linton es, sin dudas, las relaciones entre la cultura y la personalidad:

No puede dudarse que exista una estrecha relación entre esta configuración de la personalidad y la cultura de la sociedad a la que el individuo pertenece. La cultura, en todo lo que sea más que una abstracción creada por el investigador, existe solo en las mentes de los individuos que componen una sociedad. Derivan de ella, todas las cualidades de sus personalidades y de la interacción de estas personalidades. Y a la inversa, la personalidad de todo individuo perteneciente a la sociedad, se desarrolla y funciona en constante asociación con su cultura. Las personalidades afectan a la cultura y la cultura a cada personalidad. (1965, p. 447) 